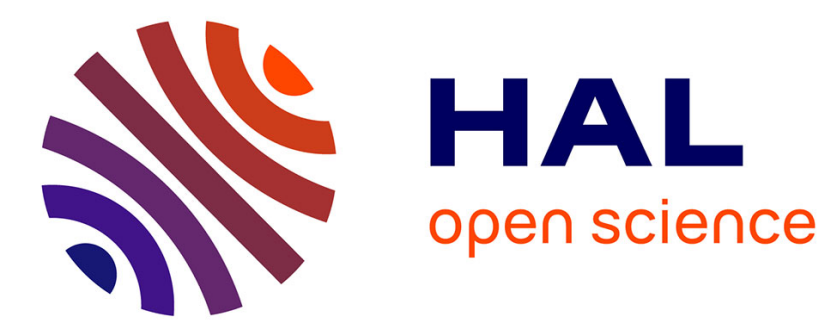

\title{
Statistical analysis of an ionospheric parameter as a base for earthquake prediction
}

Mei Li, Michel Parrot

\section{To cite this version:}

Mei Li, Michel Parrot. Statistical analysis of an ionospheric parameter as a base for earthquake prediction. Journal of Geophysical Research Space Physics, 2013, 118, pp.3731-3739. 10.1002/jgra.50313 . insu-01178983

\section{HAL Id: insu-01178983 \\ https://hal-insu.archives-ouvertes.fr/insu-01178983}

Submitted on 21 Jul 2015

HAL is a multi-disciplinary open access archive for the deposit and dissemination of scientific research documents, whether they are published or not. The documents may come from teaching and research institutions in France or abroad, or from public or private research centers.
L'archive ouverte pluridisciplinaire HAL, est destinée au dépôt et à la diffusion de documents scientifiques de niveau recherche, publiés ou non, émanant des établissements d'enseignement et de recherche français ou étrangers, des laboratoires publics ou privés. 


\title{
Statistical analysis of an ionospheric parameter as a base for earthquake prediction
}

\author{
Mei $\mathrm{Li}^{1,2,3}$ and Michel Parrot ${ }^{1}$ \\ Received 4 October 2012; revised 23 March 2013; accepted 3 May 2013; published 19 June 2013.
}

[1] This paper is related to the use of ionospheric density variations to tentatively predict earthquakes. The results of this statistical analysis are presented as a function of various parameters. The ion density was recorded by the low-altitude satellite DEMETER during more than 6 years, and a search for anomalies was automatically conducted with the complete data set. In a second time, a software checked if each anomaly could correspond to an earthquake. The search was conducted at less than $1500 \mathrm{~km}$ from the anomaly positions, and until 15 days after the anomaly time. The earthquakes have been classified depending on their magnitude, depth, and position (below the sea or inland). This attempt to predict earthquakes of course generates a lot of false alarms and wrong detections. Nevertheless, it is shown that the number of good detections increases with the magnitude of the earthquakes. In average the number of perturbations is higher the day of the earthquake, and then smoothly decreases for the days before. Earthquakes below the sea are better detected. There are seismic areas close to the South Atlantic Magnetic Anomaly and at high latitudes where the number of natural perturbations is too important to expect a high number of good detections. Finally, when there are several perturbations corresponding to a single earthquake, it is possible to combine their positions to have a better estimation of the location of the future epicenter. However, uncertainties about the time and the magnitude are large.

Citation: Li, M., and M. Parrot (2013), Statistical analysis of an ionospheric parameter as a base for earthquake prediction, J. Geophys. Res. Space Physics, 118, 3731-3739, doi:10.1002/jgra.50313.

\section{Introduction}

[2] Satellite experiments due to the vast coverage of the seismic zones of the Earth are especially regarded as suitable means for earthquake (EQ) study. Data recorded by many different satellites have been used in the past to understand the relation between preseismic ionospheric variations and seismic activity (see the review by Parrot [2009]). It was also possible to study the lithosphere-atmosphere-ionosphere coupling using data simultaneously recorded by groundbased experiments. Latest works can be found for example in Liu et al. [2009] and Kon et al. [2011]. Ionospheric perturbations have been also detected prior to the recent powerful Tohoku EQ in Japan [Ouzounov et al., 2011; Heki, 2011; He et al., 2012; Akhoondzadeh, 2012]. As a result of researches during the last 10 years, it has been shown that the ionosphere is sensitive to the seismic effect although its main behavior is dominated by the solar activity.

\footnotetext{
${ }^{1}$ Laboratoire de Physique et Chimie de l'Environnement et de l'Espace, Université d'Orléans, CNRS, Orléans, France.

${ }^{2}$ China Earthquake Networks Center, China Earthquake Administration, Beijing, China.

${ }^{3}$ China University of Geosciences, Beijing, China

Corresponding author: M. Parrot, LPC2E, CNRS-UMR7328, 3A Avenue de la Recherche, 45071 Orléans cedex 2, France. (mparrot@ cnrs-orleans.fr)

(C)2013. American Geophysical Union. All Rights Reserved. 2169-9380/13/10.1002/jgra.50313
}

[3] This is not the scope of this paper but a number of generation mechanisms have been suggested for the explanation of these precursors. The ionospheric density variations can be induced by change of the current in the global electric circuit between the bottom of the ionosphere and the Earth's surface where electric charges associated with the stressed rocks can appear [Kuo et al., 2011]. Recent hypotheses and modeling can be found for example in monographs [Hayakawa, 2009, 2012], in reviews by Pulinets [2009, 2012], Freund [2011], Pulinets and Ouzounov [2011], and references therein. In recent years, special attention has been drawn to gas release prior to earthquakes [Omori et al., 2007; Pulinets, 2007; Harrison et al., 2010; Baragiola et al., 2011] and atmospheric heating, which can be revealed with infrared experiments onboard satellites [Ouzounov et al., 2007, 2011].

[4] In this paper the total ion density given by the IAP (Instrument Analyseur de Plasma) experiment onboard the DEMETER satellite is used. The DEMETER data are presented in section 2 and, because this paper is an extension of Li and Parrot [2012], the data processing method is only briefly reviewed in section 3 . In section 4 , new results of the statistical analysis are presented. A comparison with random generated EQs is given in section 5 . The spatialtime distribution characteristics of the seismo-ionospheric effect are shown in section 6 . To confirm these results, a similar data processing with the electron density is carried out in section 7. Discussion and conclusions are provided in section 8 . 


\section{AND PARROT: EARTHQUAKE PREDICTION IN THE IONOSPHERE}

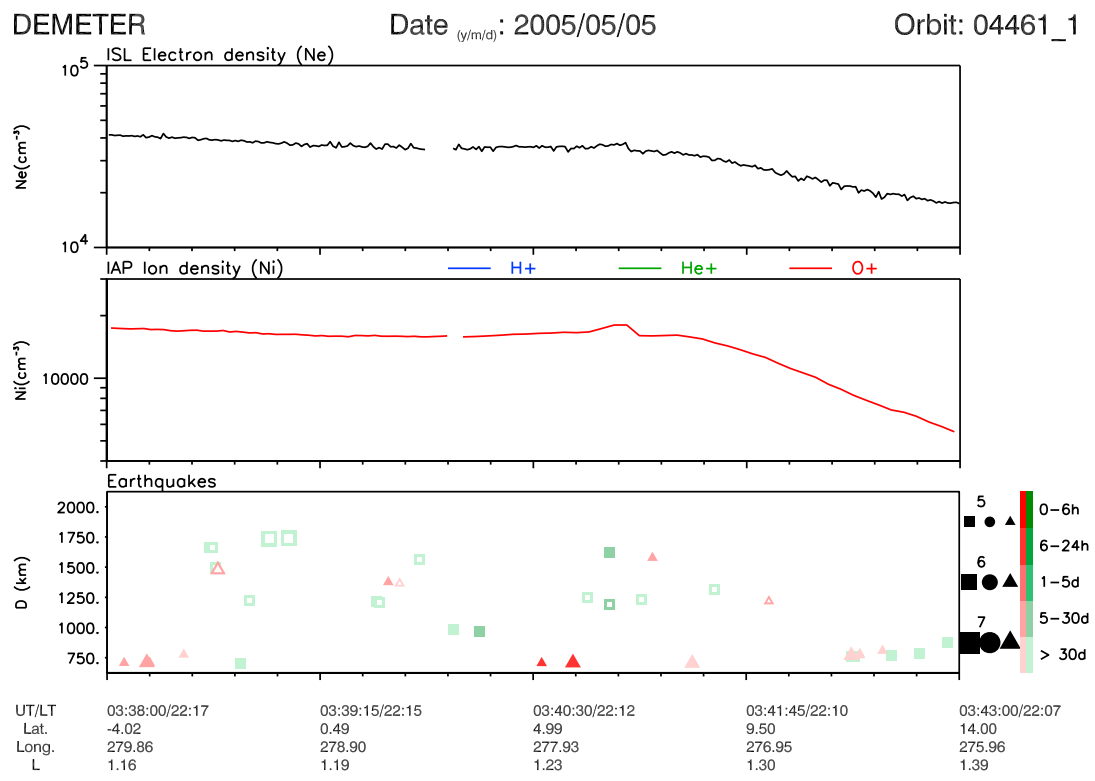

Figure 1. Data recorded on 5 May 2005 between 03.38.00 UT and 03.43.00 UT, 16 h before a $M_{w} 6.5 \mathrm{EQ}$. The top panel represents the electron density and the middle panel is devoted to the ion density. Due to the scale only the density of the $\mathrm{O}^{+}$ions is shown because they are the majority. The bottom panel is related to the distance and magnitude of coming earthquakes as function of the time. The red triangles are related to the future main shocks and aftershocks whereas the green symbols are related to past earthquakes (see text for more explanation). The parameters below the plots indicate the position of the satellite along its orbit.

\section{The Data}

[5] DEMETER was a low-altitude satellite launched in June 2004 onto a polar and circular orbit that measures electromagnetic waves and plasma parameters all around the globe except in the auroral zones [Cussac et al., 2006]. Its initial altitude of $\sim 710 \mathrm{~km}$ was lowered to $\sim 660 \mathrm{~km}$ at the end of 2005. It was the first satellite that was mainly dedicated to record seismo-electromagnetic effects on the ionosphere. It included six scientific payloads. Each of them offered long-time and continuously high-quality data to allow performing meaningful statistical studies with a much larger number of recorded events in comparison with previous ones [Parrot, 2006].

[6] The experiment IAP gives ion density with a $4 \mathrm{~s}$ time resolution and details of this experiment can be found in Berthelier et al. [2006]. As DEMETER went to its end in December 2010, it was possible to investigate the relationship between the ionospheric variations of the total ion density (the sum of $\mathrm{H}+, \mathrm{He}+$ and $\mathrm{O}+$ ) and seismic activities that took place during the satellite's lifetime.

[7] The electron density data used in this paper were recorded by the ISL (Instrument Sonde de Langmuir) experiment onboard the satellite. The time resolution is $1 \mathrm{~s}$. Details about ISL can be found in Lebreton et al. [2006].

[8] There have been accumulated reports on the ionospheric precursory effects of EQs observed by DEMETER

Table 1. EQs Considered in the Present Paper for the Ion Density Data Processing

\begin{tabular}{lcc}
\hline $4.8 \leq M_{w} \leq 5.0$ & $5.1 \leq M_{w} \leq 6.0$ & $M_{w} \geq 6.1$ \\
\hline 12057 & 8953 & 853 \\
\hline
\end{tabular}

during nighttime. A nonexhaustive list includes Parrot et al. [2006], Ouyang et al. [2008], Zhang et al. [2009a, 2009b], Akhoondzadeh et al. [2010], An et al. [2010], Bankov et al. [2010], He et al. [2010], Sarkar et al. [2011], Ouyang et al. [2011], and Píša et al. [2011]. DEMETER recorded many similar events and another example is given in Figure 1. It corresponds to an EQ occurring on 5 May 2005 at 19:12:21 UT with a magnitude equal to 6.5 and a depth equal to $18 \mathrm{~km}$. Its position was $5.71^{\circ} \mathrm{N}, 82.85^{\circ} \mathrm{W}$. From the top to the bottom, the panels show the electron density, the density of the $\mathrm{O}+$ ion, and the earthquake occurrences along the satellite orbit (at the DEMETER altitude the $\mathrm{O}+$ ions are the majority and the $\mathrm{O}+$ ion density is almost equivalent to the total ion density). The bottom panel indicates the satellite closest approach of past and future EQ epicenters that are within $2000 \mathrm{~km}$ from the DEMETER orbit. The $Y$-axis represents the distances $D$ between the epicenters and the satellite, from 750 up to $2000 \mathrm{~km}$. The symbols are filled square for postseismic events, filled triangle for preseismic events. The scale on the right represents the time interval between the EQs and the DEMETER orbit with a graduation from $>30$ days up to a $[0-6 \mathrm{~h}]$ interval. The empty symbols have similar significations except that they are related to the magnetically conjugated points of the epicenters (the distance $D$ is then the distance between these magnetically conjugated points of the epicenters and the satellite). The symbol sizes correspond to EQs of magnitude [5-6], [6-7], and [>7]. At 03:40:45 UT the red triangle indicates the closest approach to the epicenter of this EQ and the other smaller red triangle indicates an aftershock. It can be observed that there is an increase of the electron density and of the $\mathrm{O}+$ ion density close to this location. Except the correlation in time and in space between the EQ and the perturbation, there is no way to firmly attribute this ionospheric 
Table 2. Statistical Results Concerning Seismo-Ionospheric Influences on the ion Density for Different Values of the Perturbation $A(D=0-1500 \mathrm{~km}, d=0-1000 \mathrm{~km}, T=0-15 \text { Days })^{\mathrm{a}}$

\begin{tabular}{|c|c|c|c|c|c|c|c|c|c|}
\hline \multirow{2}{*}{$\frac{M_{w}}{A}$} & \multicolumn{3}{|c|}{$4.8-5.0$} & \multicolumn{3}{|c|}{$5.1-6.0$} & \multicolumn{3}{|c|}{$\geq 6.1$} \\
\hline & $\mathrm{Ng}$ & $N p$ & $N d$ & $\mathrm{Ng}$ & $N p$ & $N d$ & $\mathrm{Ng}$ & $N p$ & $N d$ \\
\hline$>0$ & 5385 & 16,563 & 1976 & 4588 & 16,102 & 1940 & 622 & 3142 & 371 \\
\hline$>5 \%$ & 4860 & 12,858 & 898 & 4184 & 12,536 & 879 & 579 & 2503 & 177 \\
\hline$>10 \%$ & 4285 & 10,042 & 510 & 3741 & 9,779 & 469 & 534 & 2009 & 95 \\
\hline$>15 \%$ & 3817 & 8,061 & 291 & 3345 & 7,816 & 265 & 491 & 1608 & 51 \\
\hline
\end{tabular}

${ }^{\mathrm{a}} \mathrm{Ng}, \mathrm{Np}$, and $\mathrm{Nd}$ stand for the number of good detections, the number of right alarms, and the number of perturbations with a decreasing trend, respectively.

perturbation to precursory effects of this EQ. Then, many cautions have been taken in the study of particular events (see for example Píša et al. [2011]), and statistical analyses of a huge number of events have been conducted. Then, it was shown by He et al. [2011] and Píša et al. [2012] that, statistically, EQs induce perturbations in the ionosphere. This was also supported by Parrot [2012] who used IAP data and compared the number of perturbations in the vicinity (time and space) of known EQs, and the number of perturbations in the vicinity of random events. In the two cases the perturbations were automatically determined by software.

\section{The Data Processing Method With the Ion Density}

[9] In this paper, all ionospheric perturbations (similar to the one shown in Figure 1) are automatically searched in the complete nighttime data set of 6.5 years, and then it is automatically checked if a perturbation could correspond to a given $\mathrm{EQ}$.

[10] First, the complete set of half-orbit IAP ion density data, which includes 96,863 nighttime data files with $27,257,933$ data points with the same sampling rate, is considered. This set is used to automatically search perturbations. Only the perturbations that comply with (i) the duration time is between 23 and $120 \mathrm{~s}$, (ii) the distance to the nearest seismic zone is less than or equal to $1500 \mathrm{~km}$ (a map of seismic activity zones was constructed using the list of EQs with $M_{w} \geq 4.8$ taking place from 1 July 2004 to 31 December 2010), and (iii) $K p$ index is less than 3 during the same day where the perturbation appears. This last requirement eliminates the effect of solar activity on the ionosphere, which is considered as one of the main confounding factors. Huge perturbation amplitudes have been also eliminated because they did not have physical meanings and they corresponded to spurious peaks (ion density is also automatically extracted from IAP raw data). Peak values are compared to background values. For example in case of increase, a maximum is first determined. This maximum being at the time $t$, a search is conducted for the two minima, which are just around $t$ (first change of the sign of the derivative on each side of the maximum). If they occur at $t 1(<t)$ and $t 2(>t)$, the perturbation is kept if $23 \mathrm{~s}<t 2-t 1<120 \mathrm{~s}$, and the background value is determined by values at $t 1$ and $t 2$. At the end, the perturbation database contains 56,139 events in all. The information for each perturbation includes peak appearing time, orbit number, location (latitude and longitude), background value, amplitude, change trend (increase or decrease; if the amplitude is larger than the background value, it is increase, if not, it is decrease), and duration time. In the following we will use the parameter $A$, which is the ratio between an increase or decrease in amplitude of the perturbations and the corresponding background value. It must be noted that, doing such process, the variation of the ion density is only considered whatever the real values of this ion density are. This will prevent problems that may occur if this ion density is not well determined (wrong absolute values) or if the satellite altitude changes as it is the case (nonhomogeneous data base).

[11] Second, the EQ database considered includes 21,863 EQs from 20 August 2004 to 31 December 2010, with $M_{w}$ $\geq 4.8$ (USGS: http://www.usgs.gov) and they are classified into three groups in the light of magnitudes $M_{w}$ (see Table 1). Table 1 shows that $55.1 \%$ of the earthquakes are with $M_{w} 4.8-5.0,41.0 \%$ with $M_{w} 5.1-6.0$, and $3.9 \%$ with $M_{w}$ being larger than or equal to 6.1 .

[12] Last, to study the possible influence of the seismic activity on the ionosphere under different conditions, $D$ is defined as the distance between the location of the perturbation on the orbit and the epicenter of an EQ, $T$ is the delay time before an EQ in days, and $d$ is the depth of an EQ. For each perturbation of the list, we need to check if this perturbation could correspond or not to one EQ under the limit conditions mentioned above (selected values of $D$ and $T$ ). If an EQ is corresponding to one or to more than one perturbation, we consider it is a good detection; if not, it is a bad detection. If a perturbation corresponds to an EQ, it is a right alarm; if not, it is a false alarm. Preliminary statistical results for different $D, T$, and $d$ have been presented in Li and Parrot [2012] and in this paper we extend the analysis for different $A$ and different positions of the EQs.

\section{Results of the Statistical Analysis}

[13] The complete results for the parameters, $D=0-1500$ $\mathrm{km}, T=0-15$ days, $A>10 \%$, and $M_{w}=4.8-5$ are the following: number of the perturbations input $=56,139$, number of perturbations complying with the limits $=26,877$, number of right alarms $N p=10,042$, number of false alarms $=$ 16,835 , number of EQs complying with the limits $=12,057$, number of good detections $\mathrm{Ng}=4285$, and number of wrong detections $=7772$. The number of right alarms $N p$ does not match that of good detections $\mathrm{Ng}$ because a given EQ can

Table 3. Statistical Results Concerning Seismo-Ionospheric Influences on the ion Density for Different Values of the Perturbation $A(D=0-1500 \mathrm{~km}, d=0-1000 \mathrm{~km}, T=0-15 \text { Days })^{\mathrm{a}}$

\begin{tabular}{|c|c|c|c|c|c|c|c|c|c|c|}
\hline$M_{w}$ & \multicolumn{3}{|c|}{$4.8-5.0$} & \multicolumn{3}{|c|}{$5.1-6.0$} & \multicolumn{3}{|c|}{$\geq 6.1$} & \\
\hline$A$ & $r$ & $n$ & $s$ & $r$ & $n$ & $s$ & $r$ & $n$ & $s$ & FA \\
\hline
\end{tabular}

\begin{tabular}{lllllllllll}
\hline$>0$ & $44.7 \%$ & 3.1 & $88.1 \%$ & $51.2 \%$ & 3.5 & $88.0 \%$ & $72.9 \%$ & 5.1 & $88.2 \%$ & $22.9 \%$
\end{tabular} $\begin{array}{llllllllllll}>5 \% & 40.3 \% & 2.7 & 93.0 \% & 46.7 \% & 3.0 & 93.0 \% & 67.9 \% & 4.3 & 92.9 \% & 20.6 \%\end{array}$ $\begin{array}{lllllllllll}>10 \% & 35.5 \% & 2.3 & 94.9 \% & 41.8 \% & 2.6 & 95.2 \% & 62.6 \% & 3.8 & 95.3 \% & 18.8 \%\end{array}$ $\begin{array}{lllllllllllll}>15 \% & 31.7 \% & 2.1 & 96.4 \% & 37.4 \% & 2.3 & 96.6 \% & 57.6 \% & 3.3 & 96.8 \% & 17.2 \%\end{array}$

\footnotetext{
${ }^{\text {a }}$ Same as in Table 2 but the main results are expressed in percentage. The parameter $r$ is the percentage of good detections for earthquakes, $n$ designates the average number of perturbations for each earthquake detected, and $s$ is the ratio of the number of right alarms with the trend "increase" and the total number of right alarms. FA is the percentage of false alarms.
} 


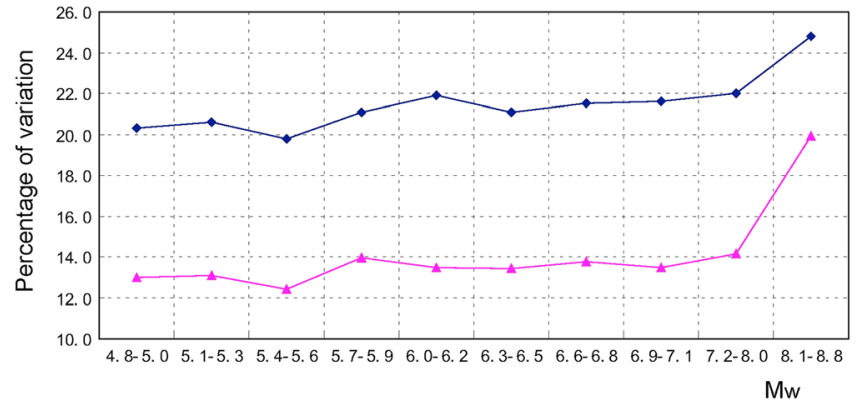

Figure 2. The blue curve shows the average of the ratio $A$ as a function of different magnitude ranges of the EQs. Because the distribution of $A$ is not Gaussian, the red curve shows the median value of $A$ as a function of different magnitude ranges of the EQs.

induce several perturbations at different times. Concerning the number of false alarms, we must take into account the number of right alarms for EQs with magnitudes larger than 5 in the same conditions (9779 for $5.1 \leq M_{w} \leq 6.0$ and 2009 for $\left.M_{w} \geq 6.1\right)$. It means that the real number of false alarms is 5047. These results are displayed in the third row of Table 2. We use different ranges for the amplitude $A$ to try to increase the number of good detections and to decrease the number of false alarms. When $A>0$ it means that all perturbations are considered, when $A>10 \%$ it means that we eliminate the small perturbations that have a ratio between the perturbation amplitude and the background amplitude less than $10 \%$. The number of perturbations complying with the limits is 46,446, 35127, 26877, and 21119 for $A$ larger than $0,5,10$, and $15 \%$, respectively. All the corresponding results (including the previous ones at the beginning of this section) are shown in Tables 2 and 3 . In these results, $n$ designates the average number of perturbations for each EQ detected, $r$ is the ratio of the number of detected EQs and that of EQs, which comply with the limit conditions, $s$ is the ratio of the number of right alarms with the trend "increase" and the total number of right alarms, and FA is the ratio of false alarms.

[14] The results in Tables 2 and 3 indicate that, whatever is the level of perturbations we select, the percentage of good detections is always increasing with the magnitude, i.e., the powerful EQs are better detected. In the same way, the average number of perturbations is also larger for these EQs. When perturbations with low amplitude are eliminated the number of good detections decreases whatever is the magnitude of the EQs, but oppositely the number of false alarms also decreases. Then, there is a tendency to say that the amplitude of the perturbations is not well related to the magnitude of the EQs. To check this, average and median values of $A$ have been plotted as a function of the magnitude of the detected EQs. The result is shown in Figure 2, and it can be seen that in fact there are larger perturbations for larger EQ magnitudes as expected. This is not well established because it is only evident for very large magnitudes. An explanation is that EQ characteristics other than the magnitude certainly play a role.

[15] It must be also noticed in Table 3 that, when we only keep perturbations with large amplitudes, the perturbations mainly correspond to increase of the density.
[16] Regarding the possible mechanisms of ionospheric perturbations by EQs, it is evident that they must take the EQ locations into account. Then, to check if there is an influence, we have shared the EQ locations in our analysis into three parts: EQs with inland epicenters, EQs with epicenters below the sea with a water depth more than $1 \mathrm{~km}$, and EQs with epicenters close to a coast (depth less than $1 \mathrm{~km}$ ). The results are shown in Tables 4 and 5. It can be seen that the percentage of good detections increases with the magnitude whatever is the location of the EQs. However, as was already noticed by Parrot [2012], the percentage of good detections is larger for EQs occurring below the sea. Furthermore, EQs taking place near coasts have the lowest percentage of good detections.

\section{Comparison With Random Generated EQs}

[17] To check the validity of the results, a comparison has been carried out with random generated EQs. To obtain random generated events, longitudes of all real EQs have been shifted by $25^{\circ}$ to the west, and we have subtracted one month to their times. This was conducted to try to keep the same ionospheric conditions because most of the earthquakes are concentrated around the equator, and it is known that, during nighttime, natural occurrence of ionospheric perturbations is also more concentrated around the equator. The one month shift of time was also to stay at the same season. From this list of new events, 30 sets of $N$ events have been randomly extracted. The number of events $N$ was chosen equal to 8000 to be close to the number of real EQs with $M_{w}=4.8-5$ or $M_{w}=5.1-6$ that we have in Table 1 . Then for each of these 30 sets the same data processing as for the real EQs has been used to estimate 30 times the parameter $r$ (the ratio between the detected events and the total number of events). At the end, the average value of $r$ for the random selected events is 42.27 and its variance is 0.15 . This value is lower than the lower value of $r$ shown in the first raw of Table 3 (44.7\% for the EQs with low magnitude).

\section{The Spatial-Time Distribution Characteristics of the Seismo-Ionospheric Effect}

[18] On one hand, while one perturbation could be attributed to a single EQ, we have also found that one EQ can correspond to more than one perturbation. On the other hand, the number of false alarms (perturbation with no EQ) is important because seismic activity is not the unique factor giving rise to ionospheric variations. Therefore, it is necessary to do some statistics about the number of perturbations for each

Table 4. Statistical Results Concerning the Seismo-Ionospheric Influences on the ion Density for Different Locations of the Earthquakes $(D=0-1500 \mathrm{~km}, d=0-1000 \mathrm{~km}, T=0-15 \text { Days, } A>0)^{\mathrm{a}}$

\begin{tabular}{|c|c|c|c|c|c|c|c|c|c|c|c|c|}
\hline$M_{w}$ & \multicolumn{4}{|c|}{$4.8-5.0$} & \multicolumn{4}{|c|}{$5.1-6.0$} & \multicolumn{4}{|c|}{$\geq 6.1$} \\
\hline Land-Sea & $\mathrm{Ne}$ & $\mathrm{Ng}$ & $N p$ & $N d$ & $\mathrm{Ne}$ & $\mathrm{Ng}$ & $N p$ & $N d$ & $\mathrm{Ne}$ & $\mathrm{Ng}$ & $N p$ & $N d$ \\
\hline Sea & 3104 & 1686 & 6703 & 851 & 2535 & 1654 & 7741 & 975 & 175 & 149 & 1016 & 152 \\
\hline Coast & 4931 & 1889 & 4957 & 535 & 3635 & 1567 & 4267 & 461 & 382 & 264 & 1188 & 112 \\
\hline Land & 4022 & 1810 & 4903 & 583 & 2783 & 1367 & 4094 & 475 & 296 & 209 & 938 & 98 \\
\hline
\end{tabular}

${ }^{\mathrm{a}} \mathrm{Ne}$ is the number of earthquakes to be detected. Same parameters as in Table 2. 
Table 5. Statistical Results Concerning the Seismo-Ionospheric Influences on the Ion Density for Different Locations of the Earthquakes $(D=0-1500 \mathrm{~km}, d=0-1000 \mathrm{~km}, T=0-15$ Days, $A>0)^{\mathrm{a}}$

\begin{tabular}{|c|c|c|c|c|c|c|c|c|c|}
\hline \multirow{2}{*}{$\frac{M_{w}}{\text { Land-Sea }}$} & \multicolumn{3}{|c|}{$4.8-5.0$} & \multicolumn{3}{|c|}{$5.1-6.0$} & \multicolumn{3}{|c|}{$\geq 6.1$} \\
\hline & $r$ & $n$ & $s$ & $r$ & $n$ & $s$ & $r$ & $n$ & $s$ \\
\hline Sea & $54.3 \%$ & 4.0 & $87.3 \%$ & $65.2 \%$ & 4.7 & $87.4 \%$ & $85.1 \%$ & 6.8 & $85.0 \%$ \\
\hline Coast & $38.3 \%$ & 2.6 & $89.2 \%$ & $43.1 \%$ & 2.7 & $89.2 \%$ & $69.1 \%$ & 4.5 & $90.6 \%$ \\
\hline Land & $45.0 \%$ & 2.7 & $88.1 \%$ & $49.1 \%$ & 3.0 & $88.4 \%$ & $70.6 \%$ & 4.5 & $89.5 \%$ \\
\hline
\end{tabular}

${ }^{\text {a }}$ Same data as in Table 4 but the results are expressed in percentage. Same parameters as in Table 3.

EQ detected. It is natural to classify the $10,595 \mathrm{EQs}$ well detected (Table 2, $A>0$ ) into three groups according to the number of their associated perturbations $1-9,10-19$, and more than or equal to 20 . The corresponding number of EQs is $10,030(94.2 \%), 503(4.2 \%)$, and $62(0.6 \%)$, respectively. Their locations are shown in a global map with different labels (see Figure 3).

[19] From Figure 3, it can be seen that EQs with 1-9 perturbations are in the main global seismic zones, especially plate-boundary interfaces, Circum-Pacific seismic belt, and Chile seismic zone. While there is a little change for the EQs corresponding to 10-19 perturbations, it happens that 62 EQs with more than 19 perturbations lie in the Southern Hemisphere in a very specific area, which is a surprising result. These $62 \mathrm{EQs}$ correspond to $25 \mathrm{EQs}$ with $4.8 \leq M_{w} \leq$ 5.0, 31 with $5.1 \leq M_{w} \leq 6.0$, and 6 with $M_{w} \geq 6.1$. The $M_{w}$ 8.8 Chile EQ that took place on 27 February 2010 is the largest one corresponding to more than 19 perturbations among the six strong EQs in this region. Moreover, it is also the only one with more than 19 perturbations among the $86 \mathrm{EQs}$ with $M_{w}>7.0$ occurring during the mission. Therefore, it means that the number of perturbations has little relationship with the magnitude of strong EQs. To check this problem, two rectangular areas have been selected in Figure 3: one where we observe a large number of perturbations per EQ, Zone1 with latmin $=-70^{\circ}$, latmax $=-45^{\circ}$, longmax $=150^{\circ} \mathrm{W}$, longmin $=20^{\circ} \mathrm{W}$, and another with much less perturbations
Table 6. Statistic Concerning Two Different Areas on the Earth's Surface for $D=0-1500 \mathrm{~km} ; d=0-1000 \mathrm{~km}, T=0-15$ Days $^{\mathrm{a}}$

\begin{tabular}{|c|c|c|c|c|c|c|c|c|}
\hline \multirow[b]{2}{*}{$A$} & \multicolumn{3}{|c|}{ Zone 1} & \multirow[b]{2}{*}{ FA } & \multicolumn{3}{|c|}{ Zone 2} & \multirow[b]{2}{*}{ FA } \\
\hline & $r$ & $n$ & $s$ & & $r$ & $n$ & $s$ & \\
\hline$>0$ & $61.9 \%$ & 5.1 & $86 \%$ & $58.6 \%$ & $14.0 \%$ & 1.5 & $87.1 \%$ & $12.7 \%$ \\
\hline$>10 \%$ & $47.5 \%$ & 3.6 & $95.9 \%$ & $59.1 \%$ & $10.0 \%$ & 1.4 & $95.0 \%$ & $13.9 \%$ \\
\hline
\end{tabular}

${ }^{\mathrm{a}} \mathrm{See}$ text for explanations.

per EQ, Zone2 with latmin $=0^{\circ}$, latmax $=30^{\circ}$, longmin $=$ $90^{\circ} \mathrm{E}$, longmax $=150^{\circ} \mathrm{E}$. The corresponding results of the statistics are shown in Table 6. From this table one can see that $r$, the number of good detections, is much more important in Zone1. Oppositely, FA, the number of false alarms is much lower in Zone2. This means that the number of perturbations not related to the seismic activity is much more important in Zone1. It allows to artificially detect more EQs, but in compensation the number of false alarms is very high. Additional evidence is revealed when the number of perturbations is checked as a function of time before the EQs.

[20] Figure 4 displays the number of perturbations as a function of days before the EQs for different cases. In each panel the results are expressed as a percentage relative to the total number of perturbations. It can be seen that for the two cases All EQ and Zone2, we obtain a variation that is intuitively expected, i.e., the number of perturbations is maximum for days close to the EQ day and smoothly decreases. In the two cases All EQ and Zone2, $64.3 \%$ and $77.6 \%$ of the perturbations appear one week before the EQs, respectively. It is not the case for the detected EQs with more than 19 perturbations, which mainly correspond to Zone1. This means that the perturbations have a little relation with seismic activity in this area. A possible reason of this increase of natural ionospheric perturbations is given in the next paragraph.

[21] In the equatorial and low midlatitude ionospheric regions, the distribution of plasma is controlled by the coupled processes of plasma diffusion, $E \times B$ drifts, thermospheric neutral winds, and chemical processes [Horvath and Lovell, 2009]. The daytime (nighttime) $F$ region plasma is transported by a vertical upward (downward) $E \times B$ drift, created by

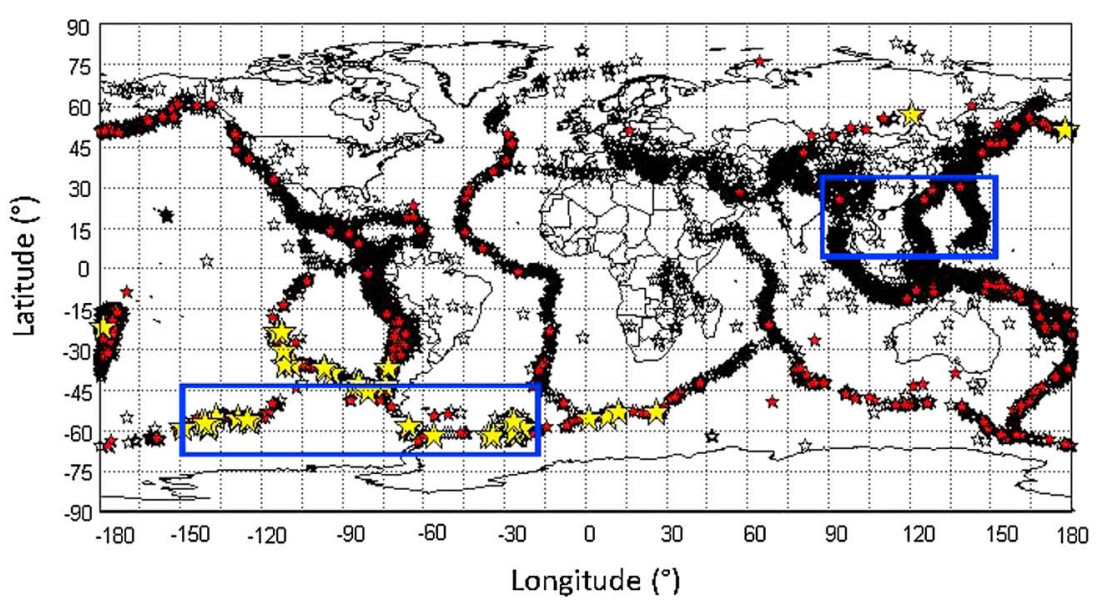

Figure 3. Distribution of all EQs with good detection corresponding to different number of perturbations. The white, red, and yellow stars are related to EQs with 1-9 perturbations, 10-19 perturbations, and more than 19 perturbations, respectively. Zone1 and Zone2 are indicated with blue rectangles (see text for explanation). 


\section{AND PARROT: EARTHQUAKE PREDICTION IN THE IONOSPHERE}
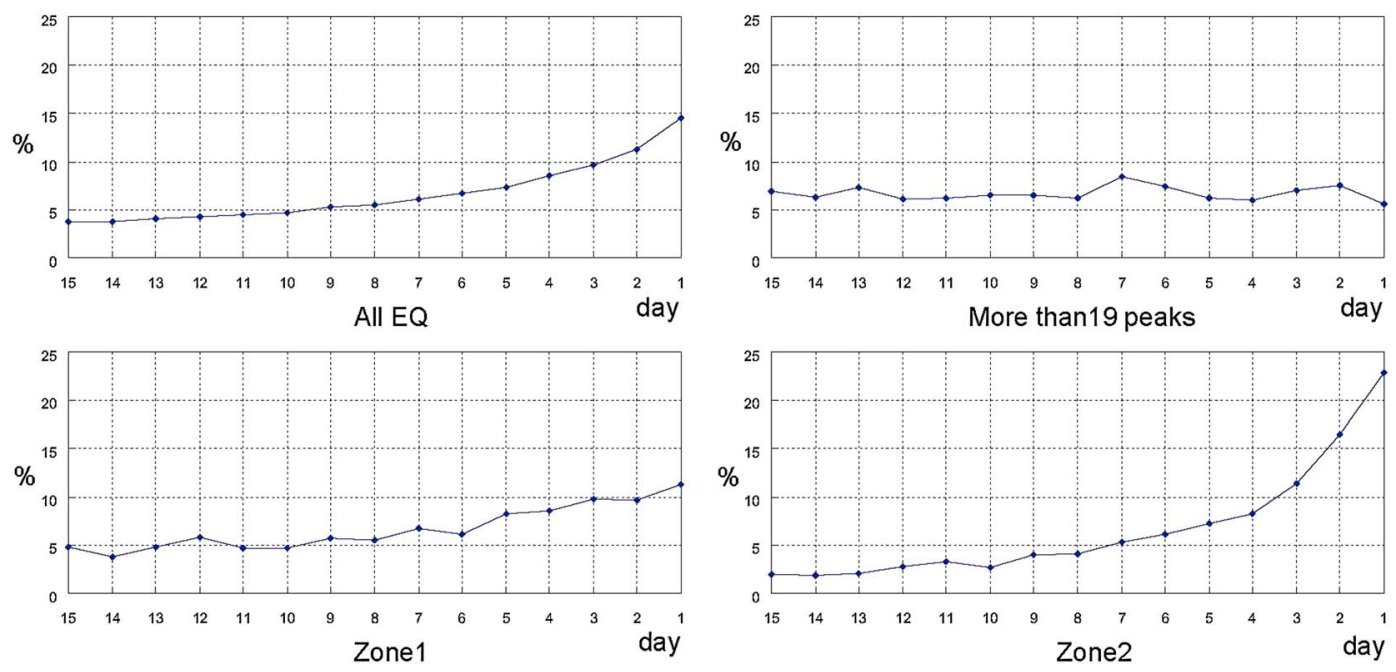

Figure 4. Variation of the number of perturbations as a function of the days before the EQs and for different cases (top left: all detected EQs, top right: detected EQs with more than 19 perturbations, bottom left: detected EQs in Zone1, bottom right: detected EQs in Zone2).

interaction between the ionospheric $E$ field and the geomagnetic $B$ field, over the dip equator, and by field-aligned diffusions on both sides of the dip equator [Hairston et al., 1997; Balan and Bailey, 1995; Balan et al., 1997]. These processes have a tendency to create a plasma distribution symmetric to the dip equator. However, this tendency is interrupted by the meridional and trans-equatorial neutral winds, which move the plasma along the magnetic field lines and produce hemispheric and interhemispheric plasma flows, respectively, and by the accompanying chemical processes [Bailey et al., 1997; Titheridge, 1995; Kil et al., 2006]. Significant longitudinal variations in plasma distribution reflect the corresponding variations of the underlying mechanisms. Major causes of such variations are related to the longitudinal variations in the $B$ field intensity and declination. Field-aligned hemispheric and interhemispheric plasma flows maximize in regions where the meridional and zonal winds have similar components. Their combination maximizes during southern winter in the $300^{\circ} \mathrm{E}-340^{\circ} \mathrm{E}$ (geographic) longitude sector, over the Atlantic. There, the declination $(D)$ is westerly and high $\left(21^{\circ}\right)$, and the field-aligned interhemispheric plasma flows are directed from the northern summer to the southern winter hemisphere [Venkatraman and Heelis, 2000]. However, over the South Atlantic, the total $B$ field intensity is anomalously low $\sim 22.8 \times 10^{3} \mathrm{nT}$ from Trivedi et al. [2005], a phenomenon known as the South Atlantic Magnetic Anomaly (SAMA), that makes the $E \times B$ drift unusually strong, because its magnitude is $E \times B / B^{2}$ [Kendall and Pickering, 1967]. Furthermore, there are special electrodynamic effects in the SAMA region that can further increase the magnitude of the $E \times B$ drift by increasing the $E$ field. Because of these plasma dynamics, the plasma density is highly variable over the SAMA and can be anomalously low [Abdu et al., 2005]. Due to energetic particle precipitations, there is an enhanced $E$ layer ionization

Table 7. EQs Considered for the Electron Density Data Processing

\begin{tabular}{lcc}
\hline $4.8 \leq M_{w} \leq 5.0$ & $5.1 \leq M_{w} \leq 6.0$ & $M_{w} \geq 6.1$ \\
\hline 11686 & 8616 & 811 \\
\hline
\end{tabular}

over the SAMA [Abdu and Batista, 1977]. The E layer conductivity is a maximum, where the magnetic field is a minimum, at the center of the SAMA $\left(310^{\circ} \mathrm{E}, 10^{\circ} \mathrm{S}\right.$ in geographic coordinates), over south Brazil, and decreases with increasing distance away from that center, toward the African continent. This can result in a westward conductivity gradient over the SAMA (indicated as DS by Abdu et al. [2003]) that can add to the background conductivity gradient, which is also westward directed during the postsunset hours. Thus, this can create a locally high (or modified) conductivity distribution that is a regular feature of the ionosphere over the SAMA [Abdu et al., 2005]. According to their model simulations, this increased conductivity will create a significantly stronger vertical $E \times B$ at the prereversal enhancement over Brazil (east coast of South America) than over Jicamarca (west coast of South America). This, combined with the fact that Zone1 is the seismic zone, which is at the highest geomagnetic latitude, make the number of ionospheric perturbations higher than in another seismic region.

\section{Data Processing With the Electron Density}

[22] To confirm the results obtained with the ion density variation, the electron density data from ISL have been processed. Normally, the total ion density and the electron density, which are recorded by the two distinct instruments IAP and ISL, must be equal; however, as said in section 3, it is not always the case and it is the reason why we only consider the relative variation of the densities. Figure 1 is a typ-

Table 8. Statistical Results Concerning Seismo-Ionospheric Influences on the Electron Density $(D=0-1500 \mathrm{~km}, d=0-1000$ $\mathrm{km}, T=0-15$ Days $)^{\mathrm{a}}$

\begin{tabular}{|c|c|c|c|c|c|c|c|c|c|}
\hline$M_{w}$ & \multicolumn{3}{|c|}{$4.8-5.0$} & \multicolumn{3}{|c|}{$5.1-6.0$} & \multicolumn{3}{|c|}{$\geq 6.1$} \\
\hline$A$ & $\mathrm{Ng}$ & $N p$ & $N d$ & $\mathrm{Ng}$ & $N p$ & $N d$ & $\mathrm{Ng}$ & $N p$ & $N d$ \\
\hline$>0$ & 3720 & 9149 & 1629 & 3266 & 8792 & 1539 & 488 & 1602 & 257 \\
\hline
\end{tabular}

${ }^{\mathrm{a}}$ The parameters are identical to the parameters of Table 2. Results correspond to the first line of Table 2. 
Table 9. Statistical Results Concerning Seismo-Ionospheric Influences on the Electron Density $(D=0-1500 \mathrm{~km}, d=0-1000$ $\mathrm{km}, T=0-15$ Days) ${ }^{\mathrm{a}}$

\begin{tabular}{|c|c|c|c|c|c|c|c|c|c|c|}
\hline$M_{w}$ & & $8-5$ & & & $1-6$ & & & $\geq 6.1$ & & \\
\hline$A$ & $r$ & $n$ & $s$ & $r$ & $n$ & $s$ & $r$ & $n$ & $S$ & FA \\
\hline
\end{tabular}

${ }^{\text {a }}$ Same as in Table 8 but the main results are expressed in percentage. The parameters are identical to the parameters of Table 3 . Results correspond to the first line of Table 3 .

ical example where the ion density is not equal to the electron density although the shape of their variations is identical. For the analysis carried out in this paper the only important point is that they present a maximum at the same time.

[23] The ISL data used here are from 17 November 2004 to 31 December 2010. The seismic activity zones were constructed using the list of EQs with $M_{w} \geq 4.8$ taking place from 1 July 2004 to 31 December 2010. The EQs used in the second software are selected from 1 December 2004 to 31 December 2010, with $M_{w} \geq 4.8$, and the number is 21,113 . They are classified into three groups as shown in Table 7. The data processing is exactly the same as for the ion density data. The ISL data have been averaged to have a time resolution similar to the IAP data (4 s) and the peak's duration is set to be $20-120 \mathrm{~s}$. The total number of peaks detected is 32,627 and the number of the peaks meeting the limit conditions is 26,874. The results are displayed only for $A>0$, i.e., all perturbations are considered. They are shown in Tables 8 and 9 and they can be compared with the ion density results in Tables 2 and 3. It is observed that:

[24] 1. The results are almost similar in the sense that we observe the same variation, i.e., the percentage of perturbations increases with the EQ magnitude as it was with the ion density.

[25] 2. The average number of perturbations (the parameter $n$ in the Table 9) also increases with the magnitude.

[26] 3. The only one difference is that the number of detected perturbations is not so large. However, this was expected because the peaks in the electron density are not so sharp than the peaks in the ion density (then the number of detected peaks is not so important). This can be observed in Figure 1 and in the numerous events that were published before in relation with the seismic activity (see section 2 ).
[27] 4. Another point to mention is that the percentage of the perturbations with decrease of the electron density is a little bit lower than that of the ion density, which may be related to the fact that the determination of the ion density sometimes does not fit with the values of the electron density.

\section{Discussion and Conclusions}

[28] This study deals with EQ prediction but in fact it could not be used as a real prediction because the uncertainty about the time is large (15 days), the uncertainty about the location is also important (within $1500 \mathrm{~km}$ ), and the magnitude is not precisely known. However, we have shown that

[29] 1. The percentage of good detections of EQs always increases with the magnitude (this is independently shown either with the ion density or with the electron density). This percentage is lower if the same data processing is applied to random generated events.

[30] 2. On average, the amplitude of the perturbations is related to the magnitude of the EQs.

[31] 3. On average, the number of perturbations is higher the day of the EQ and then gradually decreases for the days before.

[32] 4. There are seismic areas on the Earth's surface where it will not be possible to use ionospheric parameters for EQ prediction because the number of natural ionospheric perturbations is too large.

[33] 5. EQs occurring below the sea are better detected.

[34] The obtained results are not very good because not all ionospheric perturbations are caused by EQs and the number of false alarms is large. These ionospheric perturbations may be due to other sources, such as solar activity, acoustic gravity waves, travelling ionospheric disturbances, plasma dynamics as explained in section 6 , and large meteorological phenomena. It is shown that the number of false alarms can decrease if small perturbations are eliminated, but on the contrary the number of good detections also decreases, which is not really to be desired.

[35] The number of wrong detections is also important and can be explained by the fact that the satellite is above a seismic area only a few minutes per day, and that we do not expect continuous perturbations from a given EQ. Thus, possible perturbations could be missed. It is feasible to reduce this number of wrong detections if several satellites are (a) Chile $M_{\mathrm{w}} 8.8 \mathrm{EQ}$

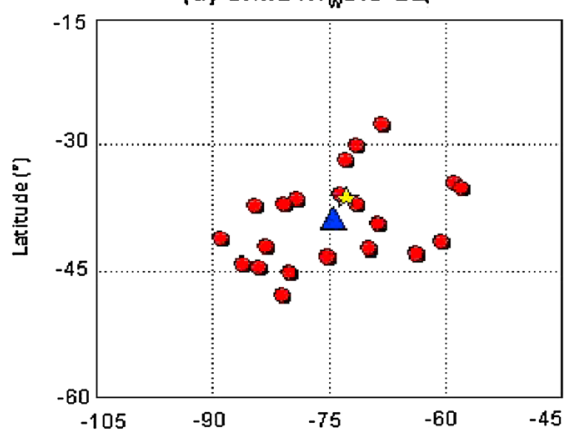

(b) Pacific $M_{\mathrm{w}} 6.3 \mathrm{EQ}$

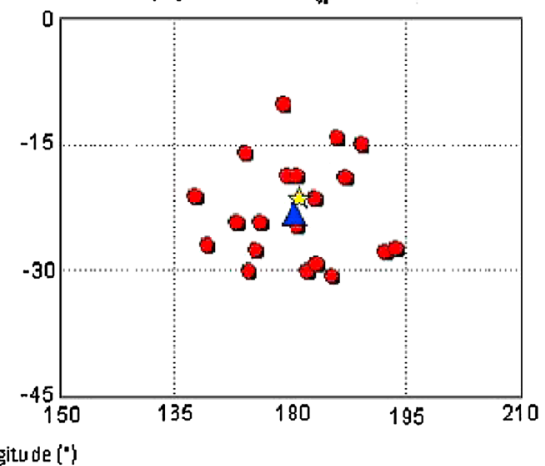

Figure 5. (a) $M_{w} 8.8$ Chile EQ in 2010; (b) $M_{w} 6.3$ Pacific EQ. The real positions of the EQ epicenters are indicated by a yellow star. The blue triangles show the positions of the EQ epicenters automatically determined from the positions of the ionospheric perturbations indicated by red stars (see text for explanation). 


\section{AND PARROT: EARTHQUAKE PREDICTION IN THE IONOSPHERE}

simultaneously used. In the future the ESA (European Space Agency) SWARM mission will have three satellites in the ionosphere, and in China they have a project of several satellites devoted to this topic [Shen et al., 2011].

[36] From a perturbation at a given location, a search for an EQ has been automatically carried out within $1500 \mathrm{~km}$ of this point. Then the determination of the EQ epicenter is not accurate, but it can be improved if we consider EQs that are well detected several times. It is possible to use the various locations of the perturbations attributed to a given EQ to have a better estimation of the epicenter position. As an example this was carried out in the cases of the $M_{w} 8.8$ Chile EQ that occurred in 2010 [see also Píša et al., 2011] and the $M_{w} 6.3$ Pacific EQ that occurred on 19 November 2007. The results are shown in Figure 5, which displays the positions of the perturbations, the position of the epicenter, and the point that is at a minimum distance from all the perturbations. It appears that this point (the blue triangle) is at $\left(74.5^{\circ} \mathrm{W}\right.$, $38.7^{\circ} \mathrm{S}$ ) not so far from the real epicenter (the yellow star), which is at $\left(72.9^{\circ} \mathrm{W}, 36.1^{\circ} \mathrm{S}\right)$ for the $M_{w} 8.8$ Chile EQ (Figure 5a). A similar result is also obtained for the Pacific $M_{w} 6.3$ EQ (Figure 5b) showing that the predicted point (the blue triangle) at $\left(179.4^{\circ} \mathrm{W}, 23.2^{\circ} \mathrm{S}\right)$ is near the real epicenter (the yellow star) at $\left(178.8^{\circ} \mathrm{W}, 21.2^{\circ} \mathrm{S}\right)$. It means that when a cluster of perturbations appears in the ionospheric data set in a given area during a few days, it is possible to approximately locate some events.

[37] Acknowledgments. This work was supported by the Centre National d'Etudes Spatiales. It is based on observations with the plasma analyzer IAP and the Langmuir probe ISL embarked on DEMETER. The author thanks J.J. Berthelier and J.P. Lebreton the PIs of these instruments for the use of the data. The research leading to these results has also received funding from the European Community's Seventh Framework Program (FP7/2007-2013) under grant agreement 262005.

\section{References}

Abdu, M. A., and I. S. Batista (1977), Sporadic E-layer phenomena in the Brazilian magnetic anomaly: Evidence for a regular particle ionization source, J. Atmos. Terr. Phys., 39, 723-732, doi:10.1016/0021-9169(77) 90059-9.

Abdu, M. A., J. W. MacDougall, I. S. Batista, J. H. A. Sobral, and P. T. Jayachandran (2003), Equatorial evening pre-reversal electric field enhancement and sporadic E layer disruption: A manifestation of $\mathrm{E}$ and F region coupling, J. Geophys. Res., 108(A6), 1254, doi:10.1029/ 2002JA009285.

Abdu, M. A., I. S. Batista, A. J. Carrasco, and C. G. M. Brum (2005), South Atlantic magnetic anomaly ionization: A review and a new focus on electrodynamic effects in the equatorial ionosphere, J. Atmos. Sol. Terr. Phys., 67, 1643-1657, doi:10.1016/j.jastp.2005.01.014.

Akhoondzadeh, M. (2012), Anomalous TEC variations associated with the powerful Tohoku earthquake of 11 March 2011, Nat. Hazards Earth Syst. Sci., 12, 1453-1462.

Akhoondzadeh, M., M. Parrot, and M. R. Saradjian (2010), Electron and ion density variations before strong earthquakes $(M>6.0)$ using DEMETER and GPS data, Nat. Hazards Earth Syst. Sci., 10, 7-18.

An, Z., Y. Fan, J. Liu, D. Tan, J. Chen, G. Zheng, and T. Xie (2010), Analysis on ion temperature variation detected by DEMETER before 2008 Wenchuan Ms8.0 earthquake, Acta Seismol. Sin., 32(6), 754-759 (in Chinese with English abstract).

Bailey, G. J., N. Balan, and Y. Z. Su (1997), The Sheffield University plasmasphere-ionosphere model: A review, J. Atmos. Terr. Phys., 59, 1541-1552, doi:10.1016/S1364-6826(96)00155-1.

Balan, N., and G. J. Bailey (1995), Equatorial plasma fountain and its effects: Possibility of an additional layer, J. Geophys. Res., 100(21), 421-21,432, doi:10.1029/95JA01555.

Balan, N., G. J. Bailey, M. A. Abdu, K. I. Oyama, P. G. Richard, J. MacDougall, and I. S. Batista (1997), Equatorial plasma fountain and its effects over three locations: Evidence for an additional layer, the F3 layer, J. Geophys. Res., 102(2), 2047-2056, doi:10.1029/95JA02639.
Bankov, L. G., M. Parrot, R. A. Heelis, J.-J. Berthelier, P. G. Marinov, and A. K. Vassileva (2010), DEMETER and DMSP satellite observations of the disturbed H+ $\mathrm{O}+$ ratio caused by Earth's seismic activity in the Sumatra area during December 2004, Adv. Space Res., 46(4), 419-430.

Baragiola, R. A., C. A. Dukes, and D. Hedges (2011), Ozone generation by rock fracture: Earthquake early warning?, Appl. Phys. Lett., 99, 204101, doi:10.1063/1.3660763.

Berthelier, J. J., M. Godefroy, F. Leblanc, E. Seran, D. Peschard, P. Gilbert, and J. Artru (2006), IAP, the thermal plasma analyzer on DEMETER, Planet. Space Sci., 54, 487-501.

Cussac, T., M. A. Clair, P. Ultré-Guerard, F. Buisson, G. Lassalle-Balier, M. Ledu, C. Elisabelar, X. Passot, and N. Rey (2006), The DEMETER microsatellite and ground segment, Planet. Space Sci., 54(5), 413-427.

Freund, F. (2011), Pre-earthquake signals: underlying physical processes, J. Asian Earth Sci., 41, 383-400.

Hairston, M. R., R. Heelis, and F. Rich (1997), Analysis of the ionospheric cross polar cap potential drop and polar ion convection patterns during the January 1997 CME events using DMSP data, Eos. Trans. AGU, 78, 264.

Harrison, R. G., K. L. Aplin, and M. J. Rycroft (2010), Atmospheric electricity coupling between earthquake regions and the ionosphere, J. Atmos. Sol. Terrestr.. Phys., 72, 376-381.

Hayakawa, M. (2009), Electromagnetic Phenomena Associated with Earthquakes, 279 pp., Transworld Research Network, Trivandrum (India).

Hayakawa, M. (2012), The Frontier of Earthquake Prediction Studies, 794 p., Nihon-Senmontosho-Shuppan, Japan.

He, Y., D. Yang, R. Zhu, J. Qian, and M. Parrot (2010), Variations of electron density and temperature in ionosphere based on the DEMETER ISL data, Earthq. Sci., 23(4), 349-355, doi:10.1007/s11589-010-0732-8.

He, Y., D. Yang, J. Qian, and M. Parrot (2011), Response of the ionospheric electron density to different types of seismic events, Nat. Hazards Earth Syst. Sci., 11, 2173-2180, doi:10.5194/nhess-11-2173-2011.

He, L. M., L. X. Wu, S. Pulinets, S. J. Liu, and F. Yang (2012), A nonlinear background removal method for seismo-ionospheric anomaly analysis under a complex solar activity scenario: A case study of the M9.0 Tohoku earthquake, Adv. Space Res., 50, 211-220.

Heki, K. (2011), Ionospheric electron enhancement preceding the 2011 Tohoku-Oki earthquake, Geophys. Res. Lett., 38, L17312, doi:10.1029/ 2011 GL047908.

Horvath, I., and B. C. Lovell (2009), Distinctive plasma density features of the topside ionosphere and their electrodynamics investigated during southern winter, J. Geophys. Res., 114, A01304, doi:10.1029/ 2008JA013683.

Kendall, P. C., and W. M. Pickering (1967), Magnetoplasma diffusion at F2region altitudes, Planet. Space Sci., 15, 825-833, doi:10.1016/0032-0633 (67)90118-3.

Kil, H., R. DeMajistre, L. J. Paxton, and Y. Zhang (2006), Nighttime F region morphology in the low and middle latitudes seen from DMSP F15 and TIMED/GUVI, J. Atmos. Sol. Terr. Phys., 68, 1672-1681, doi:10.1016/j.jastp.2006.05.024.

Kon, S., M. Nishihashi, and K. Hattori (2011), Ionospheric anomalies possibly associated with $\mathrm{M} \geq 6.0$ earthquakes in the Japan area during 1998-2010: Case studies and statistical study, J. Asian Earth Sci., 41, 410-420, doi:10.1016/j.jseaes.2010.10.005.

Kuo, C. L., J. D. Huba, G. Joyce, and L. C. Lee (2011), Ionosphere plasma bubbles and density variations induced by pre-earthquake rock currents and associated surface charges, J. Geophys. Res., 116, A10317, doi:10.1029/2011JA016628.

Lebreton, J. P., et al. (2006), The ISL Langmuir probe experiment processing onboard DEMETER: Scientific objectives, description and first results, Planet. Space Sci., 54, 472-486.

Li, M., and M. Parrot (2012), "Real time analysis" of the ion density measured by the satellite DEMETER in relation with the seismic activity, Nat. Hazards Earth Syst. Sci., 12, 2957-2963, doi:10.5194/nhess-12-2957-2012.

Liu, J. Y., et al. (2009), Seismo-ionospheric GPS total electron content anomalies observed before the 12 May 2008 Mw7.9 Wenchuan earthquake, J. Geophys. Res., 114, A04320, doi:10.1029/2008JA013698.

Omori, Y., Y. Yasuoka, H. Nagahama, Y. Kawada, T. Ishikawa, S. Tokonami, and M. Shinogi (2007), Anomalous radon emanation linked to preseismic electromagnetic phenomena, Nat. Hazards Earth Syst. Sci., 7, 629-635.

Ouyang, X., X. Zhang, X. Shen, J. Liu, J. Qian, J. Cai, and S. Zhao (2008), Ionospheric Ne disturbances before 2007 Puer, Yunnan, China, earthquake, Acta Seismol. Sinica, 21(4), 425-437, doi:10.1007/s11589-008-0425-8.

Ouyang, X., X. Zhang, X. Shen, J. Huang, J. Liu, Z. Zeren, and S. Zhao (2011), Disturbance of O+ density before major earthquake detected by DEMETER satellite, Chin. J. Space Sci., 31(5), 607-617 (in Chinese with English abstract).

Ouzounov, D., D. Liu, K. Chunli, G. Cervone, M. Kafatos, and P. Taylor (2007), Outgoing long wave radiation variability from IR satellite data prior to major earthquakes, Tectonophysics, 431(1-4), 211-220. 


\section{AND PARROT: EARTHQUAKE PREDICTION IN THE IONOSPHERE}

Ouzounov, D., S. Pulinets, A. Romanov, A. Romanov, K. Tsybulya, D. Davidenko, M. Kafatos, and P. Taylor (2011), Atmosphere-ionosphere response to the M9 Tohoku earthquake revealed by multi-instrument space-borne and ground observations: Preliminary results, Earthquake Sci., 24(6), 557-564, doi:10.1007/s11589-011-0817-z.

Parrot, M. (2006), First results of the DEMETER micro-satellite, Special Issue of, Planet.Space Sci., 54(5), 411-558.

Parrot, M. (2009), Anomalous seismic phenomena: View from space, in Electromagnetic Phenomena Associated with Earthquakes, edited by M. Hayakawa, pp. 205-233, Transworld Research Network, Kerala, India.

Parrot, M. (2012), Statistical analysis of automatically detected ion density variations recorded by DEMETER and their relation to seismic activity, Ann. Geophys., 55(1), 149-155, doi:10.4401/5270.

Parrot, M., J. J. Berthelier, J. P. Lebreton, J. A. Sauvaud, O. Santolík, and J. Blecki (2006), Examples of unusual ionospheric observations made by the DEMETER satellite over seismic regions, Phys. Chem. Earth, 31 486-495, doi:10.1016/j.pce.2006.02.011.

Píša, D., M. Parrot, and O. Santolík (2011), Ionospheric density variations recorded before the 2010 Mw8.8 earthquake in Chile, J. Geophys. Res., 116, A08309, doi:10.1029/2011JA016611.

Píša, D., F. Němec, M. Parrot, and O. Santolík (2012) Attenuation of electromagnetic waves at the frequency $\sim 1.7 \mathrm{kHz}$ in the upper ionosphere observed by the DEMETER satellite in the vicinity of earthquakes, Ann. Geophys., 55(1), 157-163, doi:10.4401/ag-5276.

Pulinets, S. A. (2007), Natural Radioactivity, Earthquakes, and the Ionosphere, Eos. Trans. AGU, 88(20), 217.

Pulinets, S. A. (2009), Physical mechanism of the vertical electric field generation over active tectonic faults, Adv. Space Res., 44(6), 767-773, doi:10.1016/j.asr.2009.04.038.
Pulinets, S. A. (2012), Low-Latitude Atmosphere-Ionosphere Effects Initiated by Strong Earthquakes Preparation Process, Int. J. Geophys., 2012, Article ID 131842, 14, doi:10.1155/2012/131842.

Pulinets, S. A., and D. Ouzounov (2011), Lithosphere-atmosphere-ionosphere coupling (LAIC) model: An unified concept for earthquake precursors validation, J. Asian Earth Sci., 41(4-5), 371-382.

Sarkar, S., S. Tiwari, and A. K. Gwal (2011), Electron density anomalies associated with $M \geq 5.9$ earthquakes in Indonesia during 2005 observed by DEMETER, J. Atmos. Sol. Terr. Phys, 73(16), 2289-2299, doi:10.1016/j.jastp.2011.06.004.

Shen, X., X. Zhang, L. Wang, H. Chen, Y. Wu, S. Yuan, J. Shen, S. Zhao, J. Qian, and J. Ding (2011), The earthquake-related disturbances in ionosphere and project of the first China seismoelectromagnetic satellite, Earthq. Sci., 24(6), 639-650, doi:10.1007 s11589-011-0824-0.

Titheridge, J. E. (1995), Winds in the ionosphere - A review, J. Atmos. Terr. Phys., 57, 1681-1714, doi:10.1016/0021-9169(95)00091-F.

Trivedi, N. B., B. M. Pathan, N. J. Schuch, M. Barreto, and L. G. Dutra (2005), Geomagnetic phenomena in the South Atlantic anomaly region in Brazil, Adv. Space Res., 36, 021-2024, doi:10.1016/j.asr.2004.09.020.

Venkatraman, S., and R. Heelis (2000), Interhemispheric plasma flows in the equatorial topside ionosphere, J. Geophys. Res., 105(18), 457-18, 464 doi:10.1029/2000JA000012.

Zhang, X., J. Qian, X. Ouyang, X. Shen, J. Cai, and S. Zhao (2009a), Ionospheric electromagnetic perturbations observed on DEMETER satellite before Chile M7.9 earthquake, Earthq. Sci., 22, 251-255.

Zhang, X., X. Shen, J. Liu, X. Ouyang, J. Qian, and S. Zhao (2009b) Analysis of ionospheric plasma perturbations before Wenchuan earthquake, Nat. Hazards Earth Syst. Sci., 9, 1259-1266. 